\title{
Health-Related Quality of life of Complete versus Infarct artery-only Percutaneous Coronary Revascularization in Multi-vessel Disease with ST- Segment Elevation Myocardial Infarction
}

\author{
Jayaraj JC* \\ Internal Medicine, Yerevan Haybusak Medical University, Yerevan, Armenia
}

${ }^{*}$ Corresponding author: Jayaraj JC, Clinical Instructor, Internal Medicine, Yerevan Haybusak Medical University, 6 Abelian St, Yerevan 0038, Armenia, Tel: (374 77) 395 008, E-mail: joshuachadwick89@gmail.com

Citation: Jayaraj JC (2018) Health-Related Quality of life of Complete versus Infarct artery-only Percutaneous Coronary Revascularization in Multi-vessel Disease with ST-Segment Elevation Myocardial Infarction. J Clin Exp Res Cardiol 4(1): 104

Received Date: May 31, 2018 Accepted Date: June 23, 2018 Published Date: June 25, 2018

\begin{abstract}
Objective: The aim of this study was to evaluate the health-related quality of life (HRQoL) as measured by the EQ-5D (European quality of life-5 dimensions) self-report questionnaire in patients treated with complete revascularization versus infarct artery-only revascularization at index admission.
\end{abstract}

Background: The revascularization strategies for multivessel disease while undergoing primary percutaneous coronary intervention (P-PCI) on HRQoL is uncertain.

Methods and Results: STEMI patients with multivessel disease underwent either complete or between April 1, 2012, and March 31,2014 , were subdivided into those who underwent complete revascularization ( $\mathrm{n}=133$ ) or infarct-related artery (IRA)-only revascularization $(n=139)$ at index admission. The EQ-5D assessed mobility, self-care, usual activity, pain or discomfort, and anxiety or depression. Patient groups were differed at baseline by gender and prevalence of heart failure. At 2-year follow-up, both mean $( \pm$ SD) EQ-VAS and EQ-5D utility scores were lower for patients who underwent complete revascularization versus infarct artery-only revascularization $(60.00( \pm 18.8)$ vs. 59.03 ( \pm 16.9$), \mathrm{P}<0.03$, and 0.68 ( \pm 0.02$)$ vs. $0.54( \pm 0.02), \mathrm{P}<0.004$, respectively).

Conclusion: The clinically significant improvement in QoL was seen in the complete revascularization group compared with treating only the IRA at 24 months.

Keywords: QoL; Complete revascularization; Infarct-related artery; Primary percutaneous coronary angioplasty; ST-segment elevation patients; Multi-vessel disease patients

\section{Introduction}

Primary percutaneous coronary intervention (P-PCI) is one of the procedures of revascularization for patients with ST-segment elevation myocardial infarction (STEMI) [1]. During index angiography, about 30\% of patients with multi-vessel disease (MVD) have $\geq 70 \%$ stenoses seen in 1 or more non-infarct-related arteries (N-IRA) having an adverse prognostic predictor of long-term outcome such as major adverse cardiac events (MACE) [2] .

\section{Complete versus infarct artery-only in STEMI with MVD}

Current guidelines recommend treating STEMI patients presented with MVD with percutaneous coronary intervention (PCI) or coronary artery bypass grafting (CABG) [3]. The purpose of PCI in patients with STEMI and MVD is to restore epicardial flow and myocardial perfusion in the significantly narrowed artery(ies) [3,4] The severity in narrowing of arteries varies from patient to patient.9 In acute STEMI patients presented with MVD, the completely occluded coronary artery which caused the MI is referred to as a 'infarct artery'; while the remaining significantly occluded coronary artery(ies), which did not cause the MI are referred as 'non-infarct artery(ies)'.(5) PCI for acute STEMI with MVD can be either "complete revascularization" or "infarct artery-only revascularization"[6] . "Infarct artery-only revascularization" is a type of PCI revascularization strategy, which is performed only in the infarct artery that caused the MI at the time of patient's index admission for MI. [7] "Complete revascularization" which includes not only the infarct artery revascularization at the time of patients' index admission for MI, but also revascularization of non-infarct artery(ies). Some interventionists, do primary PCI for infart artery-only and medication and will consider revascularization for non-infarct arteries only if the patients' symtptoms worsens $[8,9]$. Evaluating the effectiveness 
and efficacy of opening of all siginificantly stenosed arteries i.e., complete revascularization during primary PCI for an acute STEMI with infarct artery-only in patients with MVD is under constant investigation, [10-15] but there are only limited studies regarding health related quality of life (HRQoL), may play a significant role in selecting revascularization strategy [16].

The aim of this study was to compare in HRQoL as measured by the EQ-5D (European quality of life-5 dimensions) self-report questionnaire in patients treated with complete revascularization versus infarct artery-only revascularization.

\section{Methods}

\section{Study Design and Oversight}

The study utilized an observational, retrospective cohort design conducted between April 1, 2012, to March 31, 2014, at a tertiary care hospital from Yerevan, Armenia. The detailed study design and the inclusion and exclusion criteria have been described previously [17]. All multivessel disease patients who experienced a STEMI within 24 hours before undergoing PCI using either complete revascularization versus infarct artery-only revascularization included in our study. All patients were written consented to the procedure. The study was conducted according to the Declaration of Helsinki and approved by the Institutional review board.

\section{Inclusion Criteria}

- The study enrolled all acute STEMI patients with MVD that had primary PCI at our cardiac center during the study period.

- Patients who received complete revascularization by PCI at the index admission were included in complete PCI group [18,19] . The infarct artery-only PCI group included patients who underwent PCI at the index admission for the infarct artery-only [20]. Non-culprit artery(ies) that needed revascularization was defined as any coronary artery with $>50 \%$ narrowing [21].

\section{Exclusion Criteria}

- Prior CABG surgery or PCI.(9)

- Patients with missing medical records

- Patients with missing contact information

- Patients who did not speak Armenian

- Patients who were not residing in Armenia

- Patients who did not consent to study

\section{Measurement of Health Related Quality of Life}

Data from all patients with STEMI were prospectively recorded in a computerized database as part of the catheterization laboratory registry, regarding demographic data; pre-procedural risk factors; periprocedural complications; types of devices used; an extent of disease and lesions treated. These data were recorded at the time of the procedure and discharge by catheterization laboratory personnel. A telephone interviewer-administered structured questionnaire was used to collect data about HRQoL. Telephone interviewers were blinded about which group the patient belonged.

The EQ-5D is a five-item instrument that assesses mobility, self-care, usual activity, pain or discomfort, and anxiety or depression, with each dimension having three levels of perceived problems: no problems (level 1), some problems (level 2), and extreme problems (level 3) [22] .For this study, individual domain scores were converted to a summary index representing utility weights for the Armenian population [23]. An overall utility score are measures on a scale from 0 to 1 of a patient's strength of preference of their health status, where 0 representing "worst health state" usually death and 1 representing "ideal health state." [24]

\section{Statistical analysis}

All statistical analyses were performed using the Stata14 software package (StataCorp. 2015. Stata Statistical Software: Release12. College Station, TX: StataCorp LP). The patients were stratified into two groups: complete revascularization versus infarct arteryonly revascularization at baseline. Descriptive data obtained through EQ-5D questionnaire were reported as frequencies and percentages of patients having particular levels in particular dimensions. The frequencies of reported level 3 problems in this study were very low ( $<2 \%$ of total patients), hence for convenience, the levels were dichotomized into "no problems" (level 1$)$ and "any problem" (levels 2 and3), thereby converting dimensions into frequencies of reported problems [25]. The differences in reported problems between complete revascularization and infarct artery-only revascularization were compared using chi-square test. An independent t-test was used to detect differences between mean \pm SD of EQ VAS scores and EQ5D utility scores for patients with complete revascularization and infarct artery-only revascularization.

To assess the predictors of the EQ VAS and utility scores, multivariate stepwise linear regression models were used. The independent variables studied include age, the presence of hypertension, diabetes, sex, MACE, number of vessels involved and type of PCI revascularization.

Odds ratios (ORs; 95\% confidence intervals, 95\% CIs) for reporting problems in all the five EQ-5D questionnaire dimensions were calculated using binary regression for patients underwent complete revascularization versus infarct artery-only revascularization. $\mathbf{P}<0.05$ was considered statistically significant, whereas $\mathrm{P}<0.001$ was considered statistically highly significant. 


\section{Results}

Of 346 patients with STEMI and MVD who underwent primary PCI enrolled in the cohort study, 272 patients responded to the HRQOL questionnaire on a average of 2-year follow-up after an PCI revascularization. Out of 346, 322 patients were contacted, and 24 patients could not be contacted (out of the country, wrong numbers, no responders, missing numbers, etc). Of the 322 patients/relatives contacted by phone, 34 patients had died, 13 refused to participate and 275 patients were consented. Of the 275 consented patients, 272 patients had complete medical records and 3 patients' medical records were missing. The final sample available for the survival analysis was 306 and for the QOL and angina control analyses was 272. (Chart 1)

\section{Study Flow}

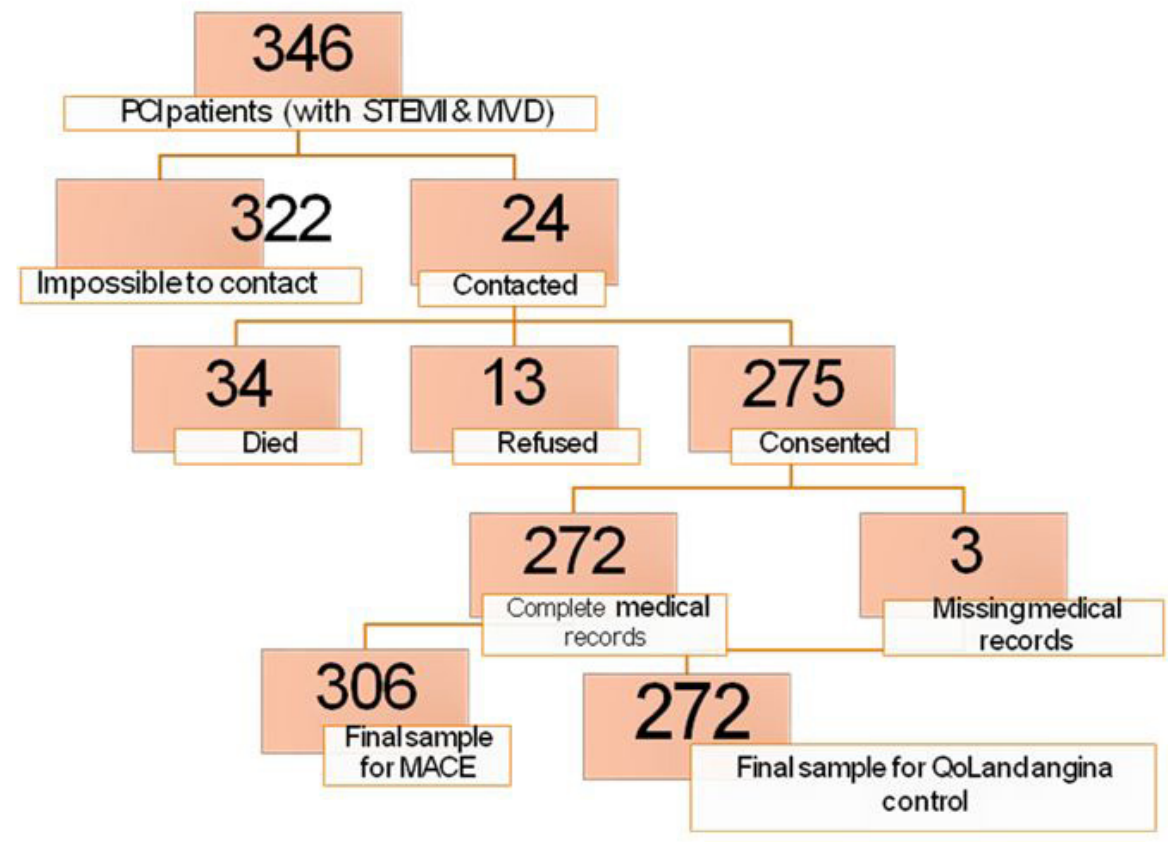

\section{Baseline clinical characteristics}

Out of 272 patients with the multi-vessel disease who underwent angioplasty within $12 \mathrm{~h}$ of AMI, 139 (51\%) received IRA-only PCI, and 133 (49\%) received complete revascularization. There were more females in the IRA-only PCI group than in the complete revascularization group $(86.4 \%$ versus $71.9 \%, \mathrm{P}=0.003)$. Regarding co-morbidities, the complete revascularization group was more likely to suffer from heart failure, and diabetes. The patients in the IRA-only group were more likely to have a prior MI. The groups were similar concerning left ventricular ejection fraction and type of stent used during the procedure. Patients' baseline characteristics stratified by PCI procedural types are presented in (Table 1 and Table 2)

\section{Health Related Quality of Life Outcomes}

Findings from outcomes of each of the five dimensions of the EQ-5D questionnaire are given in Table 3.

Differences in the dimensions between complete and infarct artery-only revascularization were observed for the anxiety/ depressions domain infarct artery-only revascularization group were significantly better compared with complete revascularization $(\mathrm{p}<0.02)$. Infarct artery-only patients were likely to experience more difficulties or problems compared with complete revascularization for all the EQ-5D dimensions, except for mobility and doing usual activities. A significantly higher proportion of infarct artery-only revascularization (vs. complete revascularization) reported self-care (33.0\%vs.38.0\%), as well as anxiety or depression (59.3\% vs. 69.3\%) $(\mathrm{P}<0.005$ in each case).

\section{EQ VAS and EQ-5D Utility Scores}

At 2-year follow-up, both mean $( \pm$ SD) EQ VAS and EQ-5D utility scores were lower for patients who underwent complete revascularization versus infarct artery-only revascularization $(60.00( \pm 18.8)$ vs. $59.03( \pm 16.9), P<0.03$, and $0.68( \pm 0.02)$ vs. 0.54 $( \pm 0.02), \mathrm{P}<0.004$, respectively).

Table 4 shows findings of the multivariate stepwise linear regression models used to assess the variables that influence on 2-year EQ VAS and EQ-5D utility scores. 


\begin{tabular}{|c|c|c|c|}
\hline Characteristics & $\begin{array}{l}\text { Complete revascularization } \\
\qquad n=133\end{array}$ & $\begin{array}{l}\text { Infarct artery-only PCI } \\
n=139\end{array}$ & $P$ value \\
\hline \multicolumn{4}{|l|}{ Demographic characteristics } \\
\hline Male & $115(86.4)$ & $100(71.9)$ & 0.003 \\
\hline Age (years),mean (SD) & $64.9(5.3)$ & $64.1(5.6)$ & 0.25 \\
\hline \multicolumn{4}{|l|}{ Risk factors and comorbidities } \\
\hline BMI $\left(\mathrm{kg} / \mathrm{m}^{2}\right)$, mean(SD) & $29.0(5.6)$ & $28.6(5.4)$ & 0.59 \\
\hline Smoking status at PCI, $\mathbf{n}(\%)$ & $21(15.7)$ & $20(14.3)$ & 0.14 \\
\hline Diabetes, n (\%) & $33(24.8)$ & $31(22.3)$ & 0.31 \\
\hline Hyperlipidemia, n (\%) & $29(21.8)$ & $30(21.5)$ & 0.02 \\
\hline Hypertension, n (\%) & $97(72.9)$ & $99(71.2)$ & $0.4-$ \\
\hline Cerebrovascular disease, $\mathbf{n}(\%)$ & $5(0.3)$ & $3(0.2)$ & 0.66 \\
\hline GI disease, $\mathbf{n}(\%)$ & $16(12.0)$ & $22(15.8)$ & 0.68 \\
\hline COPD, n (\%) & $3(0.2)$ & $2(0.1)$ & 0.27 \\
\hline \multicolumn{4}{|l|}{ Cardiacstatus } \\
\hline Anterior MI, n (\%) & $28(21.0)$ & $30(21.5)$ & 0.78 \\
\hline Unstable angina, n (\%) & $109(81.9)$ & $108(77.6)$ & 0.33 \\
\hline History of MI, n (\%) & $50(37.5)$ & $51(36.6)$ & 0.09 \\
\hline \multicolumn{4}{|l|}{$\begin{array}{c}\text { MI status by Troponin level, } \\
\text { n (\%) }\end{array}$} \\
\hline Probable MI & $79(59.3)$ & $98(70.5)$ & 0.07 \\
\hline LVEF by CMR (\%), mean (SD) & $45.5(3.9)$ & $46.0(4.0)$ & 0.23 \\
\hline
\end{tabular}

Table 1: Patient baseline characteristics

BMI: body mass index; PCI: percutaneous coronary intervention; GI: gastrointestinal; COPD: chronic obstructive pulmonary disease; MI: myocardial infarction; LVEF: left ventricular ejection fraction; CMR: cardiac magnetic resonance

\begin{tabular}{|c|c|c|c|}
\hline Characteristics & Complete revascularization & Culprit artery-only revascularization & $P$ value \\
\hline Hemodynamic unstability & $\mathrm{n}=133$ & $\mathrm{n}=139$ & \\
\hline Unstable & $4(0.3)$ & $5(0.3)$ & 0.46 \\
\hline $\begin{array}{l}\text { Killip class II/III on } \\
\text { admission }\end{array}$ & $8(0.6)$ & $12(0.8)$ & 0.51 \\
\hline TIMI flow grade $\leq 2$ in IRA & $62(46.6)$ & $79(56.8)$ & 0.005 \\
\hline \multicolumn{4}{|l|}{$\begin{array}{l}\text { Number of diseased } \\
\text { vessels, } \mathbf{n}(\%)\end{array}$} \\
\hline Two & $115(86.4)$ & $112(80.5)$ & \multirow{2}{*}{0.63} \\
\hline Three & $25(18.7)$ & $30(21.5)$ & \\
\hline $\begin{array}{c}\text { Door to balloon } \\
\text { time }(\text { min }), \text { mean }( \pm S D)\end{array}$ & $192(45.2)$ & $163(30.8)$ & $<0.001$ \\
\hline \multicolumn{4}{|l|}{ Stent approach, $\mathbf{n}(\%)$} \\
\hline Radial & $113(84.9)$ & $116(83.4)$ & 0.56 \\
\hline Femoral & $20(15.0)$ & $23(16.5)$ & \\
\hline \multicolumn{4}{|l|}{$\begin{array}{l}\text { PCI treated culprit } \\
\text { arteries, } \mathbf{n}(\%)\end{array}$} \\
\hline Proximal RCA & $28(18.7)$ & $25(15.0)$ & 0.54 \\
\hline Mild RCA* & $22(14.7)$ & $16(10.2)$ & 0.24 \\
\hline LMS & $0(0)$ & $0(0)$ & - \\
\hline Proximal LAD & $27(18.0)$ & $29(18.6)$ & 0.60 \\
\hline Mild LAD & $21(14.0)$ & $14(9.0)$ & 0.15 \\
\hline Proximal circumflex & $9(6.0)$ & $14(9.0)$ & 0.32 \\
\hline Other arteries & $18(12.0)$ & $26(16.7)$ & 0.24 \\
\hline
\end{tabular}




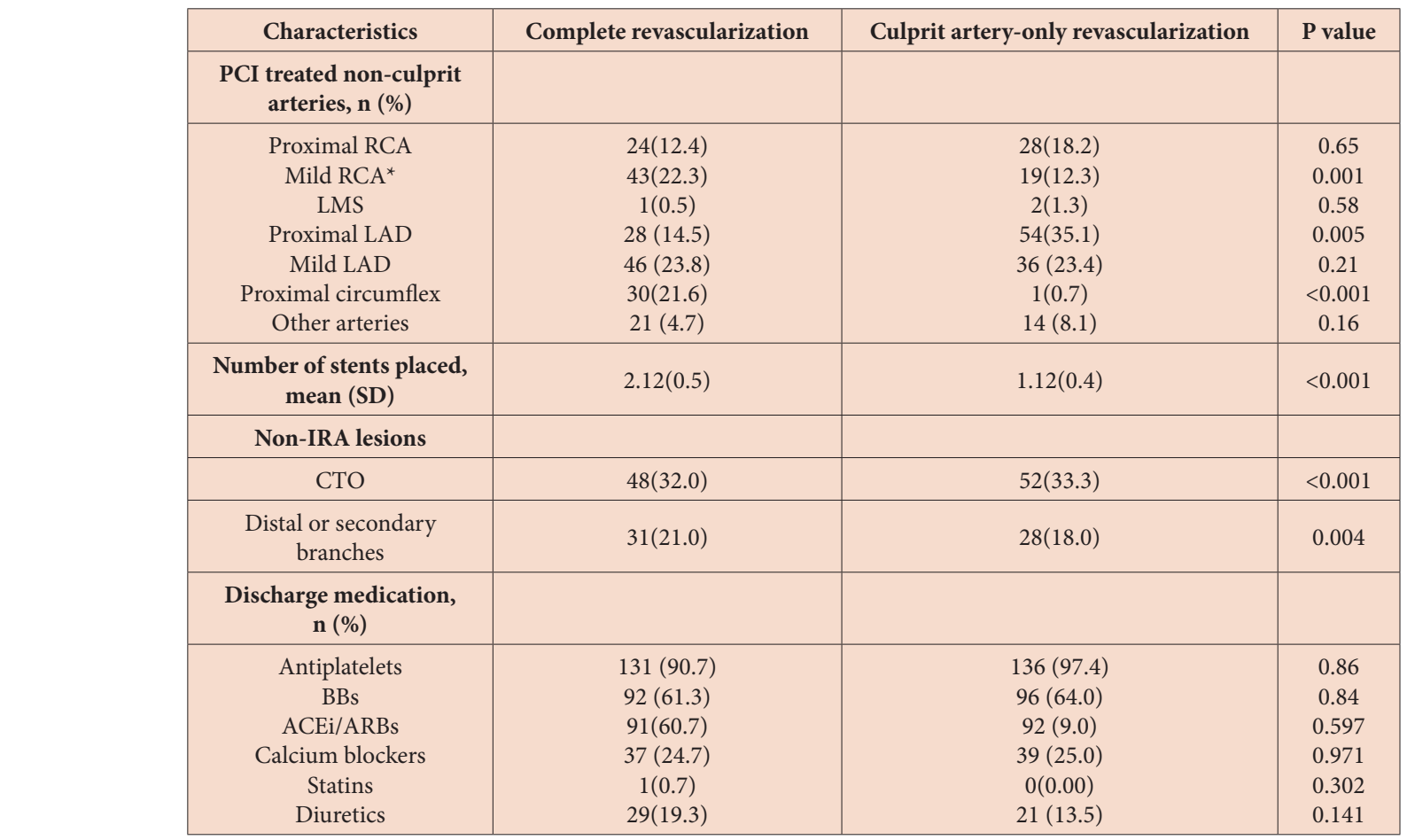

Table 2:PAngiographic characteristics of coronary arteries

*Stenosis $\geq 70 \%$.

PCI: percutaneous coronary intervention; CTO: chronic total occlusion;RCA: right coronary artery;LMs: left main stem coronary artery;LAD: left anterior descending; ACE: angiotensin-converting enzyme

\begin{tabular}{|c|c|c|c|}
\hline Dimension & Complete revascularization $\mathbf{N}=133$ & Infarct artery-only revascularization N=139 & $\mathrm{P}$ value \\
\hline Mobility, $\mathbf{n}(\%)$ & $90(67.6)$ & $92(66.1)$ & 0.02 \\
\hline Self-care, $\mathbf{n}(\%)$ & $44(33.0)$ & $54(38.8)$ & 0.01 \\
\hline Usual activities, $\mathbf{n}(\%)$ & $93(69.9)$ & $79(56.8)$ & 0.04 \\
\hline Pain/discomfort, $\mathbf{n}(\%)$ & $100(75.1)$ & $110(79.1)$ & 0.25 \\
\hline Anxiety/depression, $\mathbf{n}(\%)$ & $79(59.3)$ & $89(63.3)$ & 0.02 \\
\hline Current health status, mean VAS ( \pm SD) & $60.00( \pm 18.8)$ & $59.03( \pm 16.9)$ & 0.03 \\
\hline QoL health utility score, mean $( \pm$ SD) & $0.68( \pm 0.02)$ & $0.54( \pm 0.02)$ & 0.004 \\
\hline
\end{tabular}

EQ-5D, EuroQol five-dimensional; QoL, Quality of life.

Table 3: Proportion of patients reporting problems on each EQ-5D questionnaire dimensions on an average of 2-year follow-up

\begin{tabular}{|c|c|c|c|}
\hline Variables & $\begin{array}{l}\text { Partial regression } \\
\text { coefficient }\end{array}$ & SE & $\mathrm{P}$ \\
\hline \multicolumn{4}{|c|}{ Dependent variable: EQ VAS score* } \\
\hline $\begin{array}{l}\text { Complete vs. infarct-only artery } \\
\text { revascularization }\end{array}$ & -1.192 & 2.077 & 0.005 \\
\hline $\begin{array}{c}\text { Three vessel disease (reference: } \\
\text { Two vessel disease) }\end{array}$ & -3.241 & 2.454 & 0.001 \\
\hline Hypertension & -2.561 & 2.362 & 0.002 \\
\hline \multicolumn{4}{|c|}{ Dependent variable: EQ-5D questionnaire utility score $\dagger$} \\
\hline $\begin{array}{l}\text { Complete vs. infarct-only artery } \\
\text { revascularization }\end{array}$ & -.081 & .129 & 0.02 \\
\hline $\begin{array}{c}\text { Three vessel disease (reference: } \\
\text { Two vessel disease) }\end{array}$ & -.056 & -.056 & 0.001 \\
\hline Hypercholesterolemia & -.237 & .155 & 0.004 \\
\hline
\end{tabular}

Table 4: Predictors of EQ VAS and EQ-5D questionnaire utility scores at 2-year follow-up

Independent variables studied: age ( $<65$ vs. $>65$ years), hypertension (present vs. absent), diabetes (present vs. absent), sex (male vs. female), MACE (present vs. absent), number of vessels involved (three vs. two) and PCI intervention (complete revascularization vs. infarct-only arterty revascularization), and use of key evidence-based medication (antiplatelet agent, beta-blocker, antihyperlipidemic agent, and ACEI/ARB).

ACEI/ARB, angiotensin-converting enzyme inhibitors or angiotensin receptor blockers; CHF, congestive heart failure; EQ-5D, EuroQol five-dimensional; MACE, major adverse cardiac event; PCI, percutaneous coronary intervention; VAS, visual analogue scale.

${ }^{*} \mathrm{R}=0.09, \mathrm{R}^{2}=0.14$ adjusted $\mathrm{R} 2=0.11, \mathrm{~F}=.41, \mathrm{P}=0.04$.

$\dagger \mathrm{R}=1.09, \mathrm{R}^{2}=0.09$ adjusted $\mathrm{R} 2=0.04, \mathrm{~F}=2.32, \mathrm{P}=0.03$ 
The presence of infarct artery-only revascularization, more number of diseased vessels showed statistically highly significant negative correlation $(\mathrm{P}<0.001)$ with 2-year EQ VAS and EQ5D utility scores. Complete revascularization influenced the EQ VAS score $(\mathrm{P}<0.05$ in each case), whereas presence of hypertension were associated with worse EQ-5D utility scores at 2 year.

Binary regression models demonstrated that infarct artery-only revascularization at baseline was associated with reporting of more difficulties in patients with STEMI with MVD at 2-year follow-up for all EQ-5D questionnaire dimensions, except doing usual activities (mobility: OR 1.7 [95\% CI 1.1-12.0]; self-care: OR 1.3 [95\% CI 1.1-2.3]; pain/discomfort: OR 2.1 [95\% CI 1.85.4.]; anxiety/depression: OR 2.4.1 [95\% CI 1.3-3.8]).

\section{Discussion}

The ultimate goal of the intervention strategy for the MVD with STEMI is to increase the length of life and quality of life. Clinical outcomes which have been studied intensively, but there is only limited studies on quality of life[26] . Studies have shown that the survival time for patients treated by complete revascularization PCI was more prolonged than those treated by infarct-related artery-only revascularization[20].

Recently, the quality of life is now increasingly used as a factor in the evaluation of clinical efficacy and long-term prognosis [27]. To our knowledge, this is the first study to evaluate patients' QoL after complete versus infarct artery-only revascularization in patients with STEMI and MVCAD from Eastern Europe and Central Asia. Our study revealed interesting patterns for MVD during a STEMI were more likely male, less likely to have diabetes, or proximal left anterior descending artery lesion were treated more aggressively with the complete revascularization. Most likely, this strategy may be because of the belief that these patients may have lower procedural risk than the sicker population. Our findings underline the importance of this critical outcome for future trials, to compare these 2 revascularization strategies and to evaluate the effects of revascularization strategy on QoL [28].

Cuurrent guidelines recommended against the revascularization of the non-infarct artery unless hemodynamic compromise or residual ischemia is present [29].Our study shows that better disease-specific QoL, is associated with complete revascularization as in other studies [20]. To definitely prove this, perhaps, randomized trials that systematically measure patients' health status are needed.

\section{Study limitations}

One of the possible limitations of the study was that this is a retrospective study comprising non-randomized patients, subject to selection bias, no information regarding missing data can be provided. The sample represents responders from a single center with a modest sample size, indicating that patients who underwent PCI at other hospitals were not included in the study. Hence, the results are more applicable to the center where the study is conducted. The strength of our study was that the interviewers were blinded about which group the patient belonged. Thus, the assessment of the outcomes was blinded. Albeit most of the known risk factors were considered in models assessing predictors for EQ VAS and EQ-5D utility scores, the small values of adjusted R2 warrant further studies to other possible risk factors. Lastly, baseline analysis should be conducted to draw clear conclusions.

\section{Conclusion}

The current study assessed the difference in 2-year health realated QoL among patients with MVD and STEMI, who had undergone either complete revascularization or IRA-only PCI. The clinically significant improvement in QoL was seen in the complete revascularization group at 2-year. Considering the fact that both of the PCI types are still in use, more studies are needed to show the harms and benefits of each type and studies utilizing pre-post designs should be conducted to draw clear conclusions.

\section{Conflict of interest}

The authors have no conflict of interest to disclose.

\section{References}

1. O'Connor RE, Al Ali AS, Brady WJ, Ghaemmaghami CA, Menon V, et al. (2015) Part 9: Acute Coronary Syndromes. Circulation 132: S483-500.

2. Toma M, Buller CE, Westerhout CM, Fu Y, O’Neill WW, et al. (2010) Non-culprit coronary artery percutaneous coronary intervention during acute ST-segment elevation myocardial infarction: insights from the APEX-AMI trial. Eur Heart J 31: 1701-7.

3. O'Gara PT, Kushner FG, Ascheim DD, Casey DE, Chung MK, et al. (2013) 2013 ACCF/AHA guideline for the management of ST-elevation myocardial infarction: a report of the American College of Cardiology Foundation/American Heart Association Task Force on Practice Guidelines. J Am Coll Cardiol 61: e78-140.

4. Widimsky P, Holmes DR (2011) How to treat patients with ST-elevation acute myocardial infarction and multi-vessel disease? Eur Heart J 32 : $396-403$.

5. Baquero GA, Yadav PK, Gilchrist IC (2014) The role of multivessel coronary intervention in ST-segment elevation myocardial infarction complicated by cardiogenic shock: have we reached a verdict? Crit Care Med 42: 192-4.

6. Politi L, Sgura F, Rossi R, Monopoli D, Guerri E, et al. (2010) A randomised trial of target-vessel versus multi-vessel revascularisation in ST-elevation myocardial infarction: major adverse cardiac events during long-term follow-up. Heart 96: 662-7.

7. Kong JA, Chou ET, Minutello RM, Wong SC, Hong MK (2006) Safety of single versus multi-vessel angioplasty for patients with acute myocardial infarction and multi-vessel coronary artery disease: report from the New York State Angioplasty Registry. Coron Artery Dis 17: 71-5. 
8. Jeger R V, Pfisterer ME (2011) Primary PCI in STEMI--dilemmas and controversies: multivessel disease in STEMI patients. Complete versus Culprit Vessel revascularization in acute ST--elevation myocardial infarction. Minerva Cardioangiol 59: 225-33.

9. Pandit A, Aryal MR, Aryal Pandit A, Hakim FA, Giri S, et al. (2014) Preventive PCI versus culprit lesion stenting during primary PCI in acute STEMI: a systematic review and meta-analysis. Open Heart 1: e000012.

10. Pandit A, Aryal MR, Pandit AA, Hakim FA, Giri S, et al. (2014) Preventive PCI versus culprit lesion stenting during primary PCI in acute STEMI: a systematic review and meta-analysis. Open Heart 1: e000012.

11. Bangalore S, Kumar S, Poddar KL, Ramasamy S, Rha S-W, et al. (2011) Meta-analysis of multivessel coronary artery revascularization versus culprit-only revascularization in patients with ST-segment elevation myocardial infarction and multivessel disease. Am J Cardiol 107: 1300-10.

12. Bainey KR, Mehta SR, Lai T, Welsh RC (2014) Complete vs culprit-only revascularization for patients with multivessel disease undergoing primary percutaneous coronary intervention for ST-segment elevation myocardial infarction: a systematic review and meta-analysis. Am Heart J 167: 1-14.

13. Sethi A, Arora RR, Khosla S (2014) Complete versus culprit only revascularization for ST-elevation Myocardial infarction: A Meta-analysis of Randomized controlled trials. J Am Coll Cardiol 63: A165.

14. Sekercioglu N, Spencer FA, Lopes LC, Guyatt GH (2014) Culprit Vessel Only vs Immediate Complete Revascularization in Patients With Acute ST-Segment Elevation Myocardial Infarction : Systematic Review and Meta-Analysis. Clin Cardiol 37: 765-72.

15. Gershlick AH, Khan JN, Kelly DJ, Greenwood JP, Sasikaran T, et al. (2015) Randomized trial of complete versus lesion-only revascularization in patients undergoing primary percutaneous coronary intervention for STEMI and multivessel disease: the CvLPRIT trial. J Am Coll Cardiol 65: 963-72.

16. Jang J-S, Spertus JA, Arnold S V, Shafiq A, Grodzinsky A, et al. (2015) Impact of multivessel revascularization on health status outcomes in patients with STsegment elevation myocardial infarction and multivessel coronary artery disease. J Am Coll Cardiol 66: 2104-13.

17. Jayaraj J (2018) Clinical effectiveness of complete revascularization versus infarct-related artery-only percutaneous coronary revascularization for multivessel disease ST-segment elevation myocardial infarction. Hear India 6: 12-7

18. Hannan EL, Samadashvili Z, Walford G, Holmes DR, Jacobs AK, et al. (2010) Culprit vessel percutaneous coronary intervention versus multivessel and staged percutaneous coronary intervention for ST-segment elevation myocardial infarction patients with multivessel disease. JACC Cardiovasc Interv 3: 22-31.

19. Jensen LO, Thayssen P, Farkas DK, Hougaard M, Terkelsen CJ, et al. (2012) Culprit only or multivessel percutaneous coronary interventions in patients with ST-segment elevation myocardial infarction and multivessel disease. EuroIntervention 8: 456-64.

20. Pedersen SS, Versteeg H, Denollet J, Cheng JM, Serruys PW,et al. (2011) Patient-rated health status predicts prognosis following percutaneous coronary intervention with drug-eluting stenting. Qual Life Res 20: 559-67.

21. Dib C, Hanna EB, Chaudhry MA, Hennebry TA, Stavrakis S, et al. (2012) Culprit-vessel percutaneous coronary intervention followed by contralateral angiography versus complete angiography in patients with ST-elevation myocardial infarction. Tex Heart Inst J 39: 359-64.

22. EuroQol Group (1990) EuroQol--a new facility for the measurement of health-related quality of life. Health Policy 16: 199-208.

23. Szende A, Janssen B, Cabasés J (2014) Self-Reported Population Health: An International Perspective based on EQ-5D. 2014:31-6.

24. Dyer MT, Goldsmith KA, Sharples LS, Buxton MJ (2010) A review of health utilities using the EQ-5D in studies of cardiovascular disease. Health Qual Life Outcomes 8: 13.

25. Van Reenen M, Oppe M (2015) EQ-5D-3L User Guide Basic information on how to use the EQ-5D-3L instrument.

26. Hlatky MA (2004) Coronary revascularization and quality of life. Am Heart J 148: 5-6.

27. Chen N, Zhang J, Yang S, Li Y (2016) Impact of complete and incomplete revascularization on short- and long-term quality of life in patients with multivessel coronary artery disease. Eur Rev Med Pharmacol Sci 20: 4581-5.

28. Koltowski L, Koltowska-Haggstrom M, Filipiak KJ, Kochman J, Golicki D, et al. (2014) Quality of life in patients with ST-segment elevation myocardial infarction undergoing percutaneous coronary intervention--radial versus femoral access (from the OCEAN RACE Trial). Am J Cardiol 114: 516-21.

29. Levine GN, Bates ER, Blankenship JC, Bailey SR, Bittl JA, et al. (2016) 2015 ACC/AHA/SCAI Focused Update on Primary Percutaneous Coronary Intervention for Patients With ST-Elevation Myocardial Infarction: An Update of the 2011 ACCF/AHA/SCAI Guideline for Percutaneous Coronary Intervention and the 2013 ACCF/AHA Guideline for the Management of ST-Elevation Myocardial Infarction: A Report of the American College of Cardiology/American Heart Association Task Force on Clinical Practice Guidelines and the Society for Cardiovascular Angiography and Interventions. Circulation 133: 1135-47.

30. Spertus JA, Salisbury AC, Jones PG, Conaway DG, Thompson RC (2004) Predictors of quality-of-life benefit after percutaneous coronary intervention. Circulation 110: 3789-94.

31. Z.Z, P.K, C.J, J.A.S, W.S.W (2011) Mechanism of change in quality of life among stable coronary patients with or without percutaneous coronary intervention. Circulation 124: A12028.

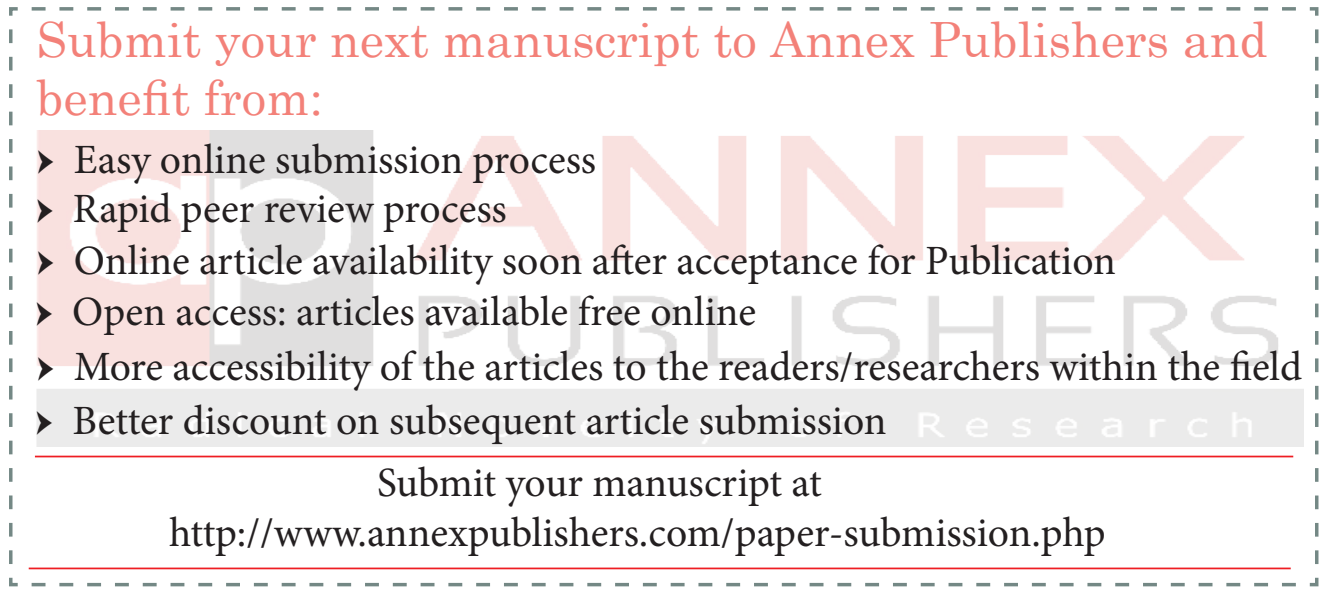

